Article

\title{
Exploring the Microalga Euglena cantabrica by Pressurized Liquid Extraction to Obtain Bioactive Compounds
}

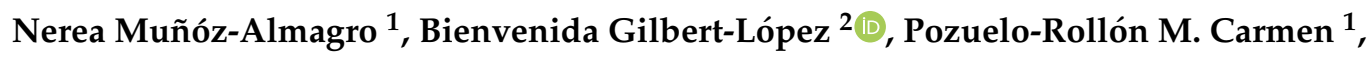 \\ Yolanda García-Fernandez ${ }^{3}$, Carlos Almeida ${ }^{3}$, Mar Villamiel ${ }^{1}$, Jose A. Mendiola ${ }^{1, *(D)}$ and \\ Elena Ibáñez ${ }^{1}$ \\ 1 Institute of Research in Food Sciences, CIAL (UAM-CSIC), Nicolás Cabrera 9, Campus Universitario de \\ Cantoblanco. 28049 Madrid, Spain; nerea.almagro@csic.es (N.M.-A.); \\ mcpozuelorollon@gmail.com (P.-R.M.C.); m.villamiel@csic.es (M.V.); elena.ibanez@csic.es (E.I.) \\ 2 Analytical Chemistry Research Group (FQM-323), Department of Physical and Analytical Chemistry, \\ University of Jaén, Campus Las Lagunillas edif. B3, 23071 Jaén, Spain; bgilbert@ujaen.es \\ 3 Spanish Bank of algae (BEA), Instituto de Oceanografía y Cambio Global (IOCAG), Fundación Canaria \\ Parque Científico y Tecnológico, Universidad de Las Palmas de Gran Canaria (ULPG), \\ 35230 Las Palmas, Canary Islands, Spain; garcia.fernandez.yolanda@gmail.com (Y.G.-F.); \\ calmeida@marinebiotechnology.org (C.A.) \\ * Correspondence: j.mendiola@csic.es
}

Received: 18 May 2020; Accepted: 9 June 2020; Published: 12 June 2020

\begin{abstract}
In the present study, the chemical composition of the microalga Euglena cantabrica was investigated. The extraction of bioactive compounds was done using pressurized liquid extraction (PLE) at different temperatures $\left(40-180{ }^{\circ} \mathrm{C}\right.$ ) and using green solvents (ethanol-water mixtures). A statistical design of experiments was used to optimize the maximum antioxidant capacity of the extracts by response surface methodology. The antioxidant capacity was determined through the inhibition of 2,2'-azino-bis-3-ethylbenzothiazoline-6-sulfonic acid (ABTS) and 1,1-diphenyl-2-picrylhydrazyl (DPPH) radicals, while the chemical analyses of the extracts were carried out using different chromatographic techniques. Chlorophylls and carotenoids were analyzed by high-performance liquid chromatography coupled to a diode array detector and mass spectrometry (HPLC-DAD-MS/MS) and carbohydrates by gas chromatography with flame ionization detection (GC-FID) and high-pressure size-exclusion chromatography coupled to an evaporative light-scattering detector (HPSEC-ELSD). The results showed different possibilities for the extraction conditions, depending on the desired bioactivity or chemical composition. Briefly, (i) mixtures of ethanol-water containing around $40 \%$ ethanol at $180^{\circ} \mathrm{C}$ gave the best antioxidant capacity, (ii) mixtures containing around $50 \%$ ethanol at $110{ }^{\circ} \mathrm{C}$ gave the best yield of $\beta$-glucan paramylon, and (iii) the use of pure ethanol at a low temperature $\left(40^{\circ} \mathrm{C}\right)$ is the best choice for the recovery of carotenoids such as diatoxanthin. Summing up, E. cantabrica seems to be a good candidate to be used in biorefinery to obtain different bioactive compounds.
\end{abstract}

Keywords: Euglena cantabrica; pressurized liquid extraction; carotenoid; carbohydrates; response surface; microalga; paramylon

\section{Introduction}

In spite of the fact that macroalgae have been used in China since 1000 b.c. and for ethnical uses in the Mayan culture and certain African tribes, they have not been used in a massive way until the middle of the 20th century. The way to cultivate them was investigated and simplified at 
the beginning of the 20th century [1]. Among others, the most important microalgal metabolites are carbohydrates, proteins, lipids, carotenoids, phenolic compounds, and phytohormones with a plethora of bioactive properties that can promote good health (bioactive compounds) [2]. Therefore, microalgae have a huge potential, because they are a vast, unexploited reservoir of new compounds that are waiting to be discovered. In fact, according 2017 estimations, a total of US \$6.5 billion is the global market value of microalgae, being US $\$ 2.5$ billion in the bioactive food ingredients category [3]. Among the different species, Euglena spp. are considered as an adequate medium for the large-scale production of metabolites without risk to humans. This is due to the extraordinary metabolic ability even comparable with multicellular organisms. It is known that Euglena spp. contain approximately $34 \%$ of carbohydrates, paramylon being the most important regarding its bioactivity and amount, up to $70-80 \%$ [4]. Among the $\beta$-glucans, paramylon is composed of only $\beta(1,3)$ bonds. Further, paramylon exists in a granular form in Euglena cells of all of species and varieties, and the number, the shape, and the uniformity of the particles of paramylon are characterized depending on the species. As it is the case with the other $\beta$-glucans, paramylon is expected to have functionality, but much remains unknown regarding the mechanism of action thereof. Its unique structural features provide techno-functional properties and modulation of the immune system, decrease of cholesterol, and control the postprandial answer of humans to glucose [5].

Euglena cantabrica is a green unicellular microalga belonging to the genus Euglena, which results from the combination of the Greek words "eu" (good) and "glene" (eyeball) and refers to the distinct eyespot that can be seen in most euglenoid cells [5]. The eyespot, also called stigma, is a photoreceptive pigment located near to the flagella and involved in the movement of the microalga in response to light intensity (phototaxis) [5]. The information about E. cantabrica available in the literature is limited and mainly related to taxonomical classifications [6-8]. Figure 1 shows the main morphological characteristics of E. cantabrica, which include the presence of spherical mucocysts, a stellate chloroplast, and a paramylon center, in addition to the eyespot and the flagella $[6,8]$.

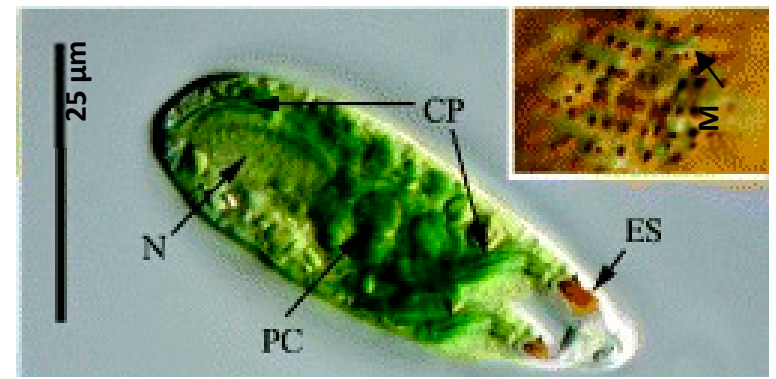

Figure 1. Microscopic view of Euglena cantabrica. N (nucleus), CP (chloroplast), ES (eyespot), PC (paramylon center), and M (mucocysts). Image from Shin and Triemer, 2004 [6] with permission of John Wiley and Sons, Ltd.

Regarding the composition of E. cantabrica, the $\beta$-1,3-glucan called paramylon is the principal reserve carbohydrate-as it is common within the genus Euglena-and it is located in structures called paramylon centers [8]. Other species from the genus Euglena, such as Euglena gracilis, have been cultivated at a large scale for the production of paramylon [9]. Nevertheless, there is no information about the recovery of paramylon or other carbohydrates from E. cantabrica. Additionally, the pigment's composition of E. cantabrica has not been studied, while the presence of astaxanthin, $\beta$-carotene, or diatoxanthin have been reported in different species of Euglena [10,11]. To the best of our knowledge, there has been published only a pioneer paper by Jerez-Martel et al. in 2017 [12] that shows the first results about the phenol compositions of E. cantabrica and the antioxidant capacity of these extracts. Conventional extraction with pure water or pure methanol was assayed in that work [12].

Recent studies have demonstrated the ability of pressurized techniques, such as pressurized liquid extraction (PLE) or supercritical fluid extraction (SFE) combined with green solvents-such as 
water, ethanol, or carbon dioxide, among others-to extract bioactive compounds from algae [2,13]. Among the advantages of PLE versus conventional extraction techniques, we can find the short extraction times, low volume used, and the possibility of extracting thermally labile compounds at high temperatures without degradation. Moreover, we can find a wide range of solvents that can be used, especially green solvents. The high pressure employed in these techniques allows the solvent to be in a liquid state above its boiling point, offering unique properties to extract valuable compounds from complex natural matrices [14]. For instance, PLE has been employed for the extraction of antioxidants from Dunaliella salina [15] and for the extraction of pigments from Neochloris oleoabundans [16] or Phaeodactylum tricornutum [17] or even carbohydrates and amino acids [18] and lipids [19]. Finally, the combination of several pressurized techniques has been revealed as a good approach for the fractionation of microalgae in a biorefinery approach [20,21]. Therefore, the objective of this study was to give an insight into the chemical composition of Euglena cantabrica in order to evaluate its potential as a source of bioactive products obtained using green technologies.

\section{Results and Discussion}

\subsection{Design of Experiments (DoE) for Pressurized Liquid Extraction (PLE)}

To optimize the extraction conditions to obtain bioactives from E. cantabrica by PLE, a design of experiments to study the interaction of two factors was selected. A factorial design type 32 (two factors at three conditions or levels) with three additional replicates in the central point was used in order to study the influence of the extraction temperatures $\left(40^{\circ} \mathrm{C}, 110^{\circ} \mathrm{C}\right.$, and $\left.180^{\circ} \mathrm{C}\right)$ and solvent compositions ( $0 \%$ ethanol (water), 50\%, and 100\%) in the response variables. This means that 12 assays were done: nine of the factorial design and three additional replicates of the central point $\left(110{ }^{\circ} \mathrm{C}, 50 \%\right.$ ethanol $)$ in order to establish the error. Those solvents were selected in order to obtain as much paramylon and carotenoids as possible, covering the widest range of temperatures possible to increase the yield. The selected response variables were the extraction yield (mass of extract per mass of dry weight, expressed in percentage), total phenols content (TPC), Trolox equivalent antioxidant capacity (TEAC) obtained by the ABTS (2,2'-azino-bis(3-ethylbenzothiazoline-6-sulfonic acid) diammonium salt) assay, and $\mathrm{EC}_{50}$ (effective concentration of extract able to decrease the concentration of a radical to the half) obtained by DPPH (1,1-diphenyl-2-picrylhydrazyl) assay. The results obtained for all the responses variables are displayed in Table 1.

Table 1. Results obtained for each response variable at the different extraction condition of Euglena cantabrica defined by the design of experiments of pressurized liquid extraction (PLE): yield, TPC, and antioxidant capacities obtained by ABTS and DPPH assays. GAE: gallic acid equivalents per gram of extract, EtOH: solvent composition, TE: Trolox equivalents, and $\mathrm{EC}_{50}$ : effective concentration of extract (in $\mu \mathrm{g} / \mathrm{mL}$ ) able to decrease the DPPH radical concentration by $50 \%$.

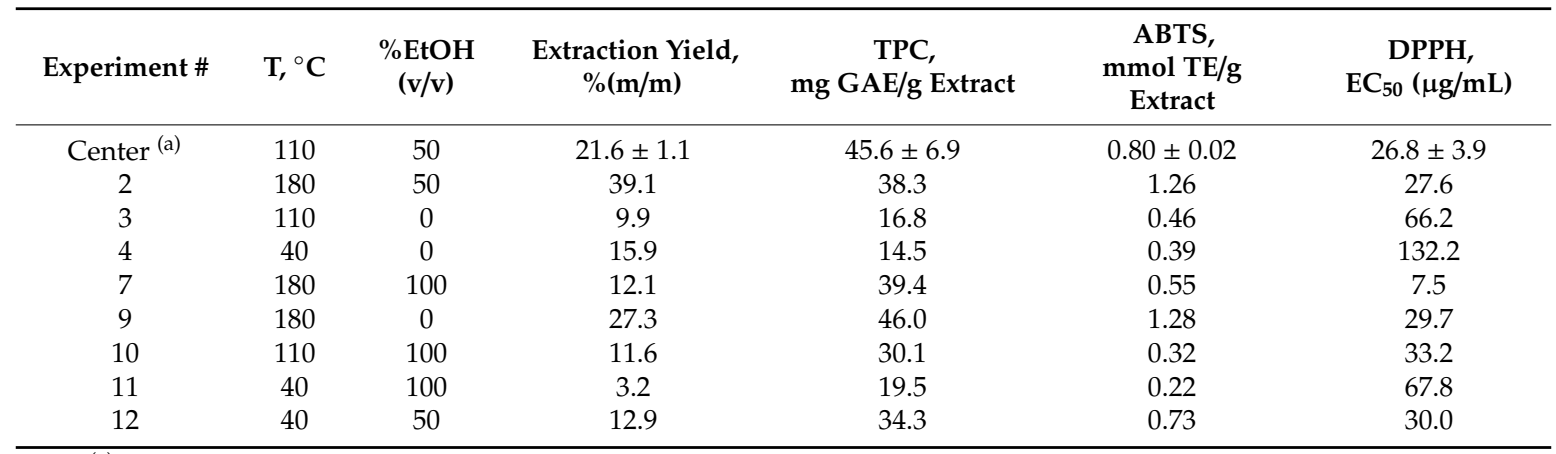

(a) Average results $( \pm \mathrm{SD})$ from the four replicates of the center points of the design of experiments (DoE) corresponding to the experiments $1,5,6$, and 8 .

The quadratic model proposed for each response variable (Yi) was:

$$
Y i=\beta_{0}+\beta_{1} \cdot A+\beta_{2} \cdot S+\beta_{1,1} \cdot A^{2}+\beta_{1,2} \cdot A \cdot B+\beta_{2,2} \cdot B^{2}+\varepsilon,
$$


where $A$ is the temperature, $B$ is the $\% \mathrm{EtOH}$ (solvent composition), $\beta_{0}$ is the intercept, $\beta_{1}$ and $\beta_{2}$ are the linear coefficients, $\beta_{1,1}$ and $\beta_{2,2}$ are the quadratic coefficients, $\beta_{1,2}$ is the interaction coefficient, and $\varepsilon$ is the error variable.

An ANOVA (analysis of variance) test was performed for each response variable, and the model adequacy was evaluated by the determination coefficient $\left(R^{2}\right)$ and the residual standard deviation (RSD) at a confidence level of $95 \%(p=0.05)$. Response surface plots were developed using the fitted quadratic polynomial obtained, and the software from the fitted model provided the optimum conditions. Pareto's diagrams, which point out the coefficients of the model that affect significantly the results together with the response surfaces, are shown in Figure 2. Following, the effects of the temperature and solvent composition on each of the response variables is discussed.

(a)

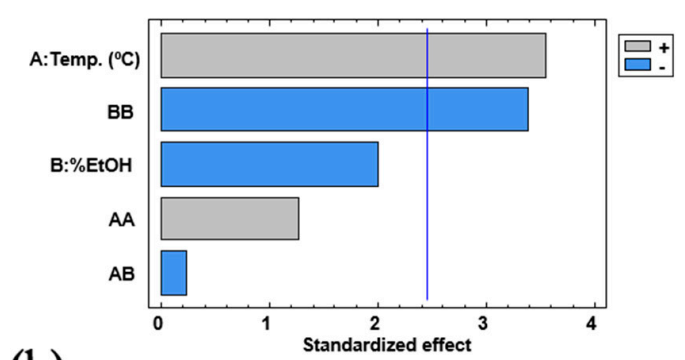

(b)

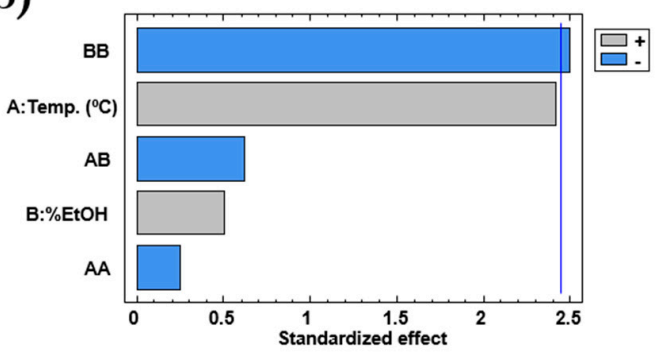

(c)

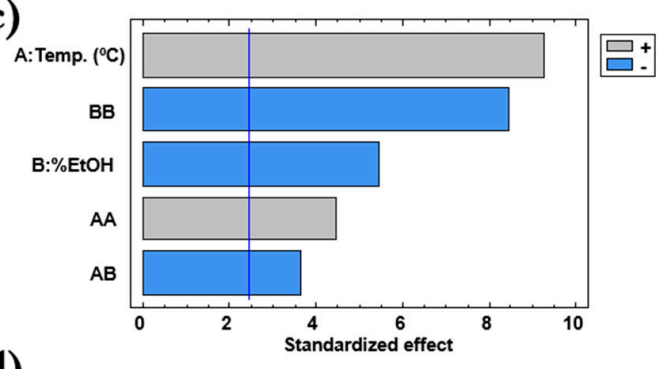

(d)

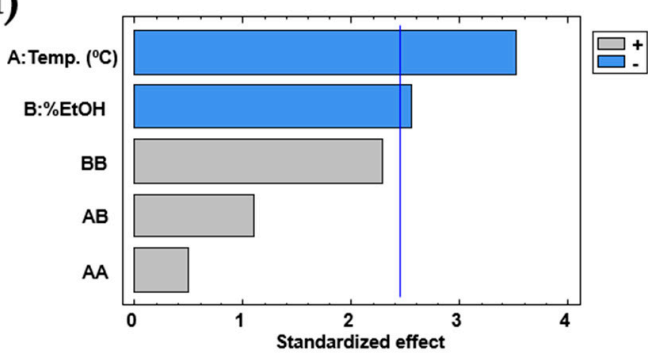

Estimated Response Surfaces
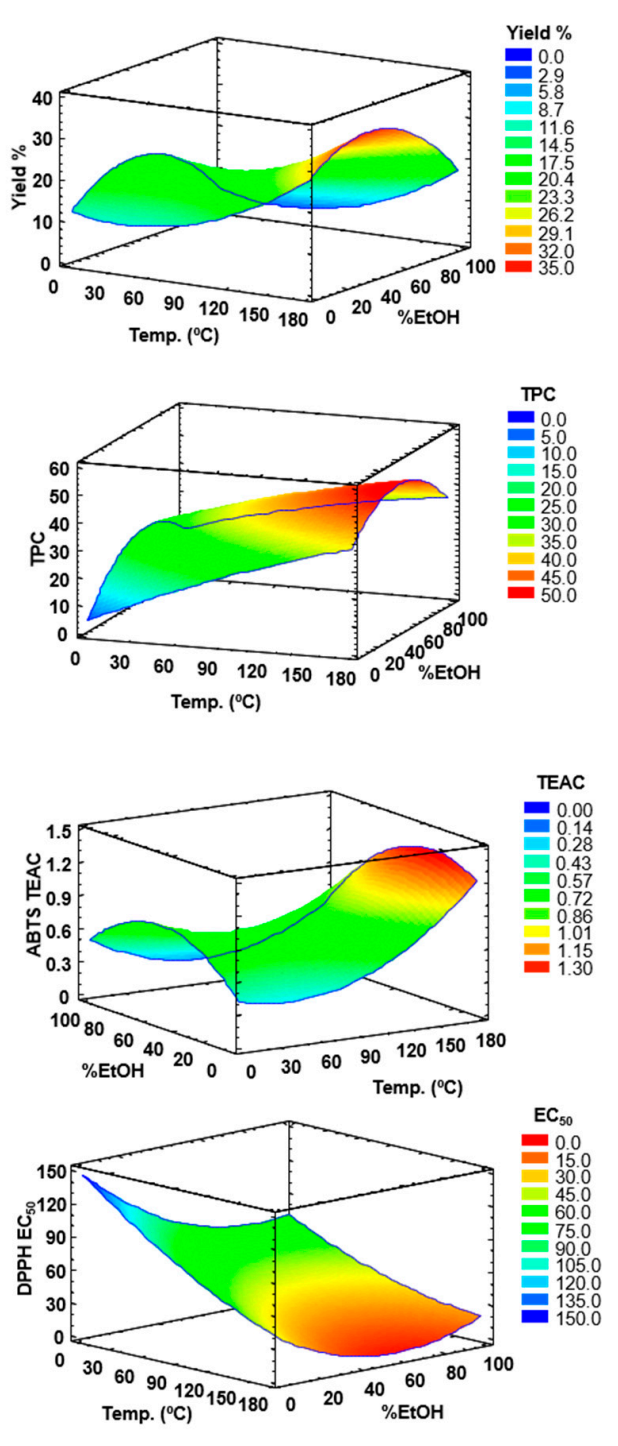

Figure 2. Pareto's diagrams and estimated response surfaces for (a) extraction yield, (b) total phenols, and antioxidant capacity measured by (c) ABTS test and (d) DPPH test. Vertical line of Pareto's diagrams shows a confidence range of $95 \%$, and the color shows if the influence of the factors is positive (increasing the value of the response variable, grey color) or negative (blue color).

Extraction yield. As it is shown in Figure 2a, the best yields are obtained using a solvent composition around $50 \%$ of ethanol. This may be due to the polarity of the extracted compounds, 
which seems to be in between water and ethanol. In addition, the extraction temperature increases the yield as a result of the increase of the compounds' solubility and decrease in solvent viscosity due to temperature; thus, an increase of the transfer ratio of the sample matter to the solvent is produced. Similar results have been reported previously for other microalgae $[17,21]$. In this case, the Pareto's diagram shows that the temperature gives the most significant influence on the extraction. The ANOVA test showed a $\mathrm{R}^{2}=0.8245$, which means that the model is able to explain $82.45 \%$ of the variability in yield, and, using this fitted model, the optimum conditions provided by the statistical software Statgraphics Centurion (version XVI) are $180^{\circ} \mathrm{C}$ and $38.7 \%$ of ethanol. The maximum yield predicted is $34.2 \%$, which is between the yields reported by Jerez-Martel et al. [12] using water (25.7\% yield) and methanol ( $57.9 \%$ yield) for $40 \mathrm{~min}$ of conventional extraction at room temperature.

Total phenols content (TPC). The TPC was measured by means of the Folin-Ciocalteau test, and the results were expressed as milligrams of gallic acid equivalents per gram of extract (mg GAE/g extract). The response surface depicted in Figure $2 \mathrm{~b}$ shows a similar trend to the extraction yield, which means that the total phenols content increases with the temperature and with an intermediate percentage of ethanol. According to the lack-of-fit test, since the $p$-value obtained (0.22) is greater than 0.05 , the model appears to be adequate for the observed data at the $95.0 \%$ confidence level. However, the model is able to explain only $69.99 \%\left(R^{2}=0.69993\right)$ of the variability in the TPC and it does not explain the close high values of the TPC obtained in the experiments using $110{ }^{\circ} \mathrm{C}, 50 \% \mathrm{EtOH}$ and using $180{ }^{\circ} \mathrm{C}, 0 \% \mathrm{EtOH}$ (see Table 1). The mathematical model proposes that the best extraction conditions to get the highest phenols content is obtained with the highest temperature $\left(180^{\circ} \mathrm{C}\right)$ using $48.4 \%$ of ethanol.

Antioxidant capacity. The antioxidant capacity of the extracts is usually determined by in vitro colorimetric assays, and those with higher antioxidant capacities are then selected for further bioactivity assays. In the present work, the antioxidant capacity of the extracts has been tested by two assays based on the ability of the extracts to reduce the concentration of different radicals, namely ABTS and DPPH. In general terms, it can be stated that more polar compounds inhibit more efficiently the ABTS radical, while less polar compounds inhibit more efficiently the DPPH radical, so different results may be observed in these assays, because they are driven by different reaction mechanisms.

The results obtained from the ABTS assay are expressed as TEAC—-that is, mmol of Trolox equivalents (TE) per gram of extract, since Trolox is used as the analytical standard. According to the Pareto's chart depicted in Figure 2c, all the coefficients of the model significantly affects the results of the TEAC values, although the most important effect is related to the temperature. The response surface is similar to those obtained for the yield and TPC variables, showing an increase of the antioxidant capacity against the ABTS radical at higher temperatures and a solvent composition close to $50 \% \mathrm{EtOH}$. The $\mathrm{R}^{2}$ coefficient indicates that the model as fitted explains $97.13 \%$ of the variability in TEAC, providing as the theoretical optimum extraction conditions a temperature of $180^{\circ} \mathrm{C}$ and a solvent composition of $30.4 \%$ of ethanol.

On the other hand, the results obtained from the DPPH scavenging test are expressed as the effective concentration of the extract (in $\mu \mathrm{g} / \mathrm{mL}$ ) able to decrease the radical concentration by $50 \%\left(\mathrm{EC}_{50}\right)$. Therefore, the higher the $\mathrm{EC}_{50}$, the lower the antioxidant capacity, since it needs a higher concentration of extract to scavenge the $50 \%$ of the DPPH radical concentration. That means that the optimization of this response variable consists of minimizing its value. The Pareto's diagram depicted in Figure $2 \mathrm{~d}$ shows that the temperature has the most important influence on the extraction, followed by the percentage of ethanol in the solvent. The $\mathrm{R}^{2}$ coefficient obtained in the ANOVA test indicates that the model as fitted explains $81.86 \%$ of the variability of the results. Since higher temperatures and higher percentages of ethanol decrease the $\mathrm{EC}_{50}$ value, it is not surprising that the extraction conditions proposed by the model to get the best antioxidant capacity are $180^{\circ} \mathrm{C}$ and $58.8 \%$ ethanol.

At this point, it is interesting to remark that the antioxidant capacity found in our PLE extracts measured by DPPH is 100-fold higher than that found by conventional solid-liquid extraction [12], despite that their yields were higher. In the work by Jerez-Martel et al. [12], using $1 \mathrm{mg} / \mathrm{mL}$, authors obtained an inhibition of $48 \%$ with water and $71 \%$ with methanol, both at room temperature. Comparing 
with our best extract at $180{ }^{\circ} \mathrm{C}, 100 \%$ ethanol, the inhibition found was $50 \%\left(\mathrm{EC}_{50}\right)$ using $7.5 \mu \mathrm{g} / \mathrm{mL}$ $(0.0075 \mathrm{mg} / \mathrm{mL}$ using their units).

\subsection{Chemical Characterization}

The chemical characterization of phenols present in E. cantabrica has been recently studied [12]; authors reported the presence of gallic acid, protocatechuic acid, (+)-catechin, chlorogenic acid, and (-)-epicatechin. In order to broaden this information, other groups of metabolites have been targeted in the present work. Different chromatographic techniques have been employed for the identification of carotenoids, chlorophylls, and carbohydrates present in the different PLE extracts. A detailed study of the lipid composition was discarded, since the total amount of lipids found in all PLE extracts of E. cantabrica was below $0.1 \%$.

The total lipid content of the extracts was calculated as the dry weight of the material soluble in $\mathrm{CHCl}_{3}: \mathrm{MeOH}(2: 1)$ from the dry PLE extract expressed as a percentage. The results showed that the lipids content is higher at higher temperatures and with high amounts of ethanol in the extraction solvent, as expected according to solvent polarity. However, in any case, the amount of lipids is not relevant (below $0.1 \%$ lipids in the extract).

2.2.1. Analysis of Pigments by Liquid Chromatography-diode Array Detection Followed by Atmospheric Pressure Chemical Ionization Tandem Mass Spectrometry (HPLC-DAD-APCI-MS/MS)

The main pigments present in E. cantabrica are carotenoids (present in the photoreceptive stigma or eye spot) and chlorophylls (the photosynthetic pigments located in the chloroplasts). In order to determine the photosynthetic pigments present in the different PLE extracts, they were analyzed by HPLC-DAD-APCI-MS/MS. A tentative identification of the pigments present in the extracts of E. cantabrica has been performed for the first time considering their retention time (Rt), the UV-Vis absorbance spectra, the mass spectrometry results, and the data available in the literature [11,22-25]. Due to their hydrophobicity, carotenoids and chlorophylls are more efficiently extracted with pure ethanol, as can be observed in Figure 3. Chromatographic peaks absorbing at $450 \mathrm{~nm}$ are significantly less intense using 50\% EtOH (Figure 3d) than using 100\% EtOH (Figure 3a-c). It can be also observed that there is a strong influence of the temperature that can cause the degradation of carotenoids pigments, as it has been suggested in other studies [14-17]. This fact can explain the different profiles shown in Figure 3. Comparing the peak abundance obtained at $180^{\circ} \mathrm{C}$ with $100 \% \mathrm{EtOH}$ (Figure 3a) with $100 \% \mathrm{EtOH}$ at $110^{\circ} \mathrm{C}$ (Figure $3 \mathrm{~b}$ ) and at $40^{\circ} \mathrm{C}$ (Figure $3 \mathrm{~b}, \mathrm{c}$, respectively), lower amounts of peaks are obtained. Moreover, the chromatogram obtained with $100 \% \mathrm{EtOH}$ at $110{ }^{\circ} \mathrm{C}$ (Figure $3 \mathrm{~b}$ ), shows an intense peak at $35.2 \mathrm{~min}$ (Figure 4, peak 28) that is not present in the other chromatograms, even though the chromatogram obtained at $40^{\circ} \mathrm{C}$ is more intense (Figure 3c). For these reasons, the extract obtained at $110^{\circ} \mathrm{C}$ has been selected to illustrate the identification of the pigments extracted by PLE from E. cantabrica (Figure 4).

The chromatogram corresponding to the sample extracted at $110{ }^{\circ} \mathrm{C}$ with $100 \%$ ethanol is shown in Figure 4. The main peak observed with a spectrum typical of carotenoids is peak number 18 $(\mathrm{Rt}=19.6 \mathrm{~min}$ ), which has been tentatively identified as diatoxanthin. On the other hand, the main peak observed with a spectrum typical of chlorophylls is peak number 28 ( $\mathrm{Rt}=35.2 \mathrm{~min}$ ), which has been identified as a pheophytin $b$. This is the main peak observed at $110^{\circ} \mathrm{C}$ (Figures $3 b$ and 4 ), and it is neither present at $40^{\circ} \mathrm{C}$ (Figure 3c) nor at $180^{\circ} \mathrm{C}$ (Figure 3a). Peak number 32 is one of the main peaks present in the extracts obtained at $40{ }^{\circ} \mathrm{C}$ and at $110^{\circ} \mathrm{C}$ and corresponds to a carotenoid that has not been identified due to an inefficient ionization. 

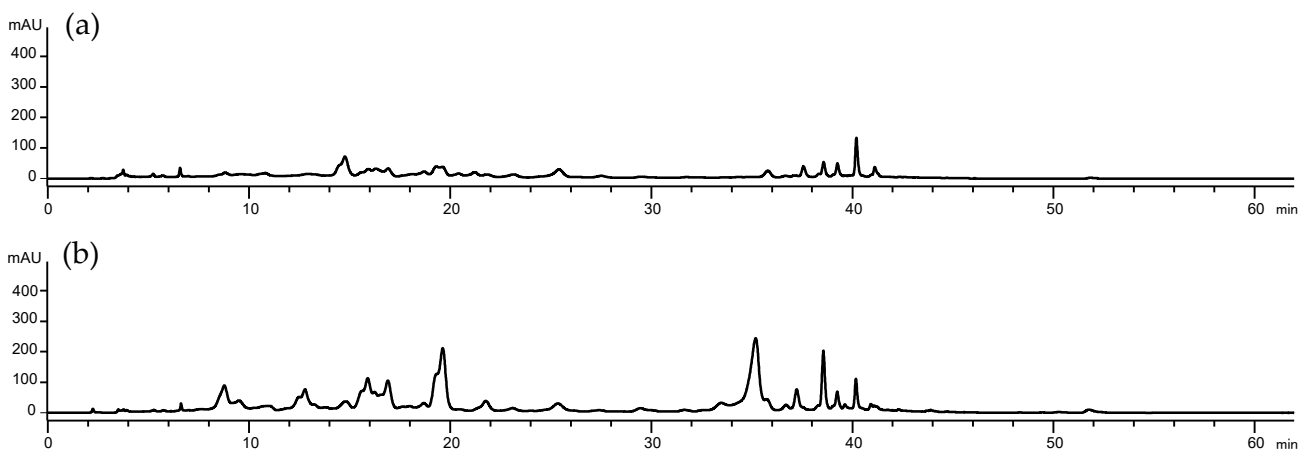

(c)
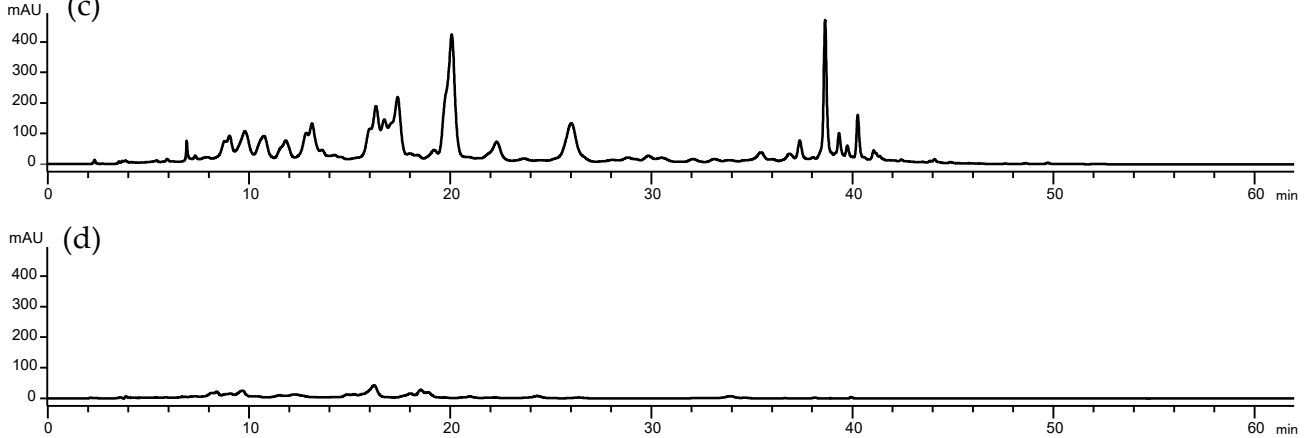

Figure 3. High-performance liquid chromatography coupled to a diode array detector (HPLC-DAD) chromatographic profile obtained at $450 \mathrm{~nm}$ from the PLE extracts carried out at (a) $180{ }^{\circ} \mathrm{C}, 100 \% \mathrm{EtOH}$ (solvent composition); (b) $110{ }^{\circ} \mathrm{C}, 100 \% \mathrm{EtOH}$; (c) $40{ }^{\circ} \mathrm{C}, 100 \% \mathrm{EtOH}$; and (d) $110^{\circ} \mathrm{C}, 50 \% \mathrm{EtOH}$.

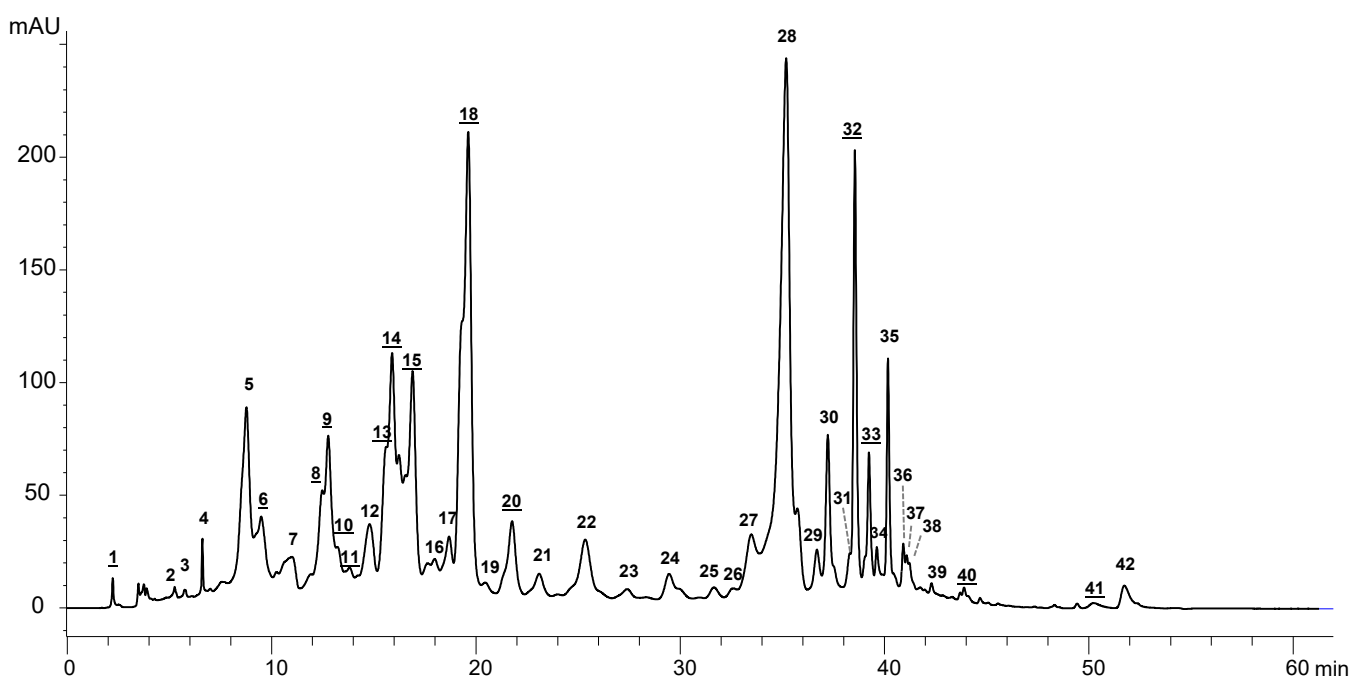

Figure 4. HPLC-DAD profile corresponding to the analysis of pigments obtained at $450 \mathrm{~nm}$ from an extract done at $110{ }^{\circ} \mathrm{C}$ and $100 \%$ ethanol. Carotenoids are represented with an underlined number and chlorophylls without underline.

The identification of all the pigments present in the PLE extract obtained at $110{ }^{\circ} \mathrm{C}$ with $100 \%$ ethanol is detailed in Table 2. In total, twenty-four chlorophyll-related compounds have been detected, together with fifteen carotenoids (peaks with underlined numbers) and three unidentified mixtures of compounds (peaks 17,36, and 42). As aforementioned, the main carotenoid present in the extract was diatoxanthin (peak 18), which has been tentatively identified according to its absorbance spectrum, its protonated molecule $(\mathrm{m} / \mathrm{z}$ 567.5), and one characteristic fragment corresponding to the dehydrated molecule $(\mathrm{m} / \mathrm{z}$ 549.7). The retention time matched with the one observed in Phaeodactylum tricornutum using a similar chromatographic method [17]. Diatoxanthin has been reported as a main carotenoid in 
microalgae from the Euglenophyta division [26] and has been previously identified in another species of the genus Euglena, namely E. sanguinea [11].

Table 2. The identification of pigments in a Euglena cantabrica PLE extract $\left(110{ }^{\circ} \mathrm{C}, 100 \%\right.$ ethanol) by HPLC-DAD-APCI-MS/MS. sh: shoulder.

\begin{tabular}{|c|c|c|c|c|c|}
\hline Peak \# & Rt (min) & Identification & Absorbance Max (nm) & Parent $m / z$ & Fragments $m / z$ \\
\hline 1 & 2.2 & Carotenoid & $272,424(\mathrm{sh}), 448,474$ & & \\
\hline 2 & 5.3 & Chlorophyll & 404,660 & & \\
\hline 3 & 5.8 & Chlorophyll & 402,662 & & \\
\hline 4 & 6.6 & Chlorophyll & 408,660 & & \\
\hline 5 & 8.8 & Chlorophyll & 438,654 & & \\
\hline 6 & 9.5 & Carotenoid & $402(\mathrm{sh}), 422,446$ & 583.6 & 491.6 \\
\hline 7 & 11.0 & Pheophorbide $a$ & 408,666 & 593.5 & $533.5,451.5$ \\
\hline 8 & 12.5 & Carotenoid & $426(\mathrm{sh}), 448$ & & \\
\hline 9 & 12.8 & Carotenoid & $426(\mathrm{sh}), 448$ & & \\
\hline 10 & 13.2 & Carotenoid & $422,446(\mathrm{sh})$ & 594.6 & 494.4 \\
\hline 11 & 13.8 & Carotenoid & 450,472 (sh) & & \\
\hline 12 & 14.8 & Pyropheophorbide b & 438,654 & 549.4 & 521.5 \\
\hline 13 & 15.6 & Carotenoid & 444,472 & & \\
\hline 14 & 15.9 & Carotenoid & 446,468 & & \\
\hline 15 & 16.9 & Carotenoid & $408(\mathrm{sh}), 430,456$ & 506.9 & 268.4 \\
\hline 16 & 18.0 & Pyropheophorbide $a$ & 412,666 & 535.5 & \\
\hline 17 & 18.7 & Not identified & & & \\
\hline 18 & 19.6 & Diatoxanthin & 450,478 & 567.5 & 549.7 \\
\hline 19 & 20.5 & Chlorophyll & 418,660 & 889.7 & $611.3,551.5$ \\
\hline 20 & 21.8 & Carotenoid & $426(\mathrm{sh}), 450,478$ & 557.7 & 291.4 \\
\hline 21 & 23.1 & Chlorophyll & 418,660 & 959.8 & \\
\hline 22 & 25.4 & $\begin{array}{l}\text { Hydroxypheophytin } \\
\text { b }\end{array}$ & $438,472(\mathrm{sh}), 654$ & 901.6 & $873.8,623.5$ \\
\hline 23 & 27.4 & Chlorophyll & 418,664 & 887.6 & $869.6,609.5$ \\
\hline 24 & 29.5 & Hydroxypheophytin & 404,666 & 887.8 & $869.8,609.5$ \\
\hline 25 & 31.7 & Chlorophyll & 416,664 & $852.1,887.8$ & \\
\hline 26 & 32.6 & Chlorophyll & 434,660 & 823.8 & $805.8,567.5$ \\
\hline 27 & 33.5 & Phoonhutin hand h' & 436,654 & 885.8 & $607.4,547.3$ \\
\hline 28 & 35.2 & Pheophytin $b$ and $b^{\prime}$ & 436,654 & 885.8 & $607.5,547.4$ \\
\hline 29 & 36.7 & & 408,666 & 871.9 & $593.5,533.5$ \\
\hline 30 & 37.2 & Pheophytin $a$ and $a^{\prime}$ & 408,666 & 871.9 & $593.5,533.5$ \\
\hline 31 & 38.3 & Chlorophyll & 418,664 & 871.9 & 856 \\
\hline 32 & 38.6 & Carotenoid & $426(\mathrm{sh}), 450,478$ & & \\
\hline 33 & 39.2 & Carotenoid & $420(\mathrm{sh}), 444,472$ & 603.6 & 265.3 \\
\hline 34 & 39.6 & Chlorophyll & 418,664 & 955.9 & $676.6,616.6$ \\
\hline 35 & 40.2 & Pyropheophytin b & 436,654 & 827.5 & 549.5 \\
\hline 36 & 40.9 & Not identified & $466,492(\mathrm{sh}), 662$ & & \\
\hline 37 & 41.1 & Pyropheophytin $a$ & 410,668 & 813.9 & 535.5 \\
\hline 38 & 41.2 & and $a^{\prime}$ & 410,668 & 813.9 & 535.5 \\
\hline 39 & 42.3 & Chlorophyll & 420,664 & & \\
\hline 40 & 43.9 & Carotenoid & $438(\mathrm{sh}), 470,502$ & 857.9 & $591.5,441.6$ \\
\hline 41 & 49.4 & Carotenoid & $468(\mathrm{sh}), 494,528$ & & \\
\hline 42 & 51.7 & Not identified & & 517.5 & $499.4,488.5$ \\
\hline
\end{tabular}

Several derivatives of both chlorophylls $a$ and $b$ have been tentatively identified according to their UV-Vis and MS spectral data [23-25], being the most intense peak of this group the one corresponding to pheophytin b (Figure 4 and Table 2, peak 28). Pheophytin b results when the $\mathrm{Mg}$ atom is removed from the tetrapyrrole ring of chlorophyll $\mathrm{b}$. It has been identified from the absorbance maxima, its protonated molecule $(\mathrm{m} / \mathrm{z}$ 885.8) and two characteristic fragments resulting from the loss of the phytyl group $(m / z 607.4)$ and the subsequent fragmentation of the propionic chain $(m / z 547.3)$. Similarly, 
peak 27-which is not the baseline separated from peak 28-has been assigned to pheophytin $\mathrm{b}^{\prime}$. Peaks 29 and 30 have been identified as pheophytin $a$ and $a^{\prime}$, showing the protonated molecule $(m / z$ 871.9) and the same fragmentation scheme described for pheophytin $b$. The compound resulting from the de-esterification of the phytyl chain of pheophytin $a$ is called pheophorbide $a(\mathrm{~m} / z$ 593.5), which has been also detected in the extract (peak 7). On the contrary, pheophorbide $b$ has not been found.

Other derivatives called pyropheophytins are formed through the decarboxylation of pheophytins and have been also identified in the PLE extract of E. cantabrica. Peak 35 has been assigned to pyropheophytin $\mathrm{b}(\mathrm{m} / \mathrm{z} 827.5)$, while peaks 37 and 38 have been identified as pyropheophytin $a$ and $a^{\prime}$ $(\mathrm{m} / \mathrm{z}$ 813.9), considering their protonated molecules and their respective fragments corresponding to the loss of the phytyl group. Pyropheophorbides are formed through the de-esterification of the phytyl chain of pyropheophytins, and both pyropheophorbide $b$ (peak $12, \mathrm{~m} / \mathrm{z} 549.4$ ) and pyropheophorbide $a$ (peak 16, $m / z$ 535.5) have been identified in the extract. Pyropheophorbide $b$ show a fragment of $m / z$ 521.5 that correspond to $\mathrm{CO}$ fragmentation, which has been reported as exclusive of chlorophyll $\mathrm{b}$ derivatives [24,25].

It is important to note that chlorophylls $a$ and $\mathrm{b}$ are located in the chloroplasts, and the development of chloroplasts in the Euglena genus is influenced by the light cycle. In addition, diatoxanthin has been associated with the photoprotection of E. gracilis during the long-term acclimation to light-induced stress [27]. Therefore, the profile of pigments in E. cantabrica depends on both the cultivation and the extraction conditions.

\subsubsection{Characterization of Carbohydrates}

In order to estimate the molecular weight $(\mathrm{Mw})$ of the carbohydrates present in the samples, a HPSEC-ELSD (high-pressure size-exclusion chromatography coupled to an evaporative light-scattering detector) analysis was carried out. The chromatographic profiles were different depending on the extraction conditions used, since the number of peaks varied from two to eight. Figure 5 shows, as an example, the profile corresponding to a sample subjected to an extraction at $110{ }^{\circ} \mathrm{C}$ with $50 \%$ of EtOH. As can be seen, several of the observed peaks, the first (labeled in Figure 5 as ${ }^{*}$ ) and the latter (labeled as ${ }^{* *}$ ), were out of the range of estimation of the method, in agreement with conditions indicated in the Materials and Methods section. The peak with a maximum of $25 \mathrm{~min}$ corresponded to an average $\mathrm{Mw}$ of $506 \mathrm{kDa}$. Previous studies have reported that other species of Euglena (E. gracilis) possesses a $\beta$-glucan (paramylon) with a Mw of $500 \mathrm{kDa}$ [28]. Therefore, it is plausible that this peak was due to paramylon. The other peaks could correspond to glycans different from paramylon with lower Mw. Although in E. gracilis, the major carbohydrate is paramylon, other more structurally complex polymers are also present [28]. Figure 6 provides detailed information about the distribution and abundance (under the chromatographic conditions here used) of the different carbohydrate fractions at different PLE conditions, according to the estimation of the Mw obtained by HPSEC-ELSD.

Regarding the distribution of the different fractions of carbohydrates found in the extractions (Figure 6), the use of $100 \% \mathrm{EtOH}$ is inadequate for the extraction of this polysaccharide, regardless of the temperature. At $0 \%$ of $\mathrm{EtOH}$, a peak with a Mw higher than paramylon is observed at $40{ }^{\circ} \mathrm{C}(696 \mathrm{kDa})$ and $110{ }^{\circ} \mathrm{C}(651.3 \mathrm{kDa})$. Considering the extractions with $50 \%$ ethanol, together with paramylon (483.1-585.2 kDa), up to four molecular species with Mw lower than $17 \mathrm{kDa}$ were observed, probably glycans that can be observed in microalgae from the same gender [28]. It is clear that temperatures of 40 and $180^{\circ} \mathrm{C}$ led to higher proportions of these poly- or oligosaccharides. Therefore, it seems that the best extraction conditions for obtaining this $\beta$-glucan could be $110{ }^{\circ} \mathrm{C}$ and $50 \%$ of EtOH. As indicated above, the presence of this polysaccharide is of great relevance, since it could affect the immune answer in a similar way as $\beta$-glucans derived from the cell wall components of fungi and bacteria. Typically, high-Mw $\beta$-glucans are taken up by macrophages, degraded intracellularly, and then released as short 
$\beta$-glucan chains extracellularly. Then, the short $\beta$-glucans stimulate macrophages and other leucocytes thereby, triggering a broad immune response [29].

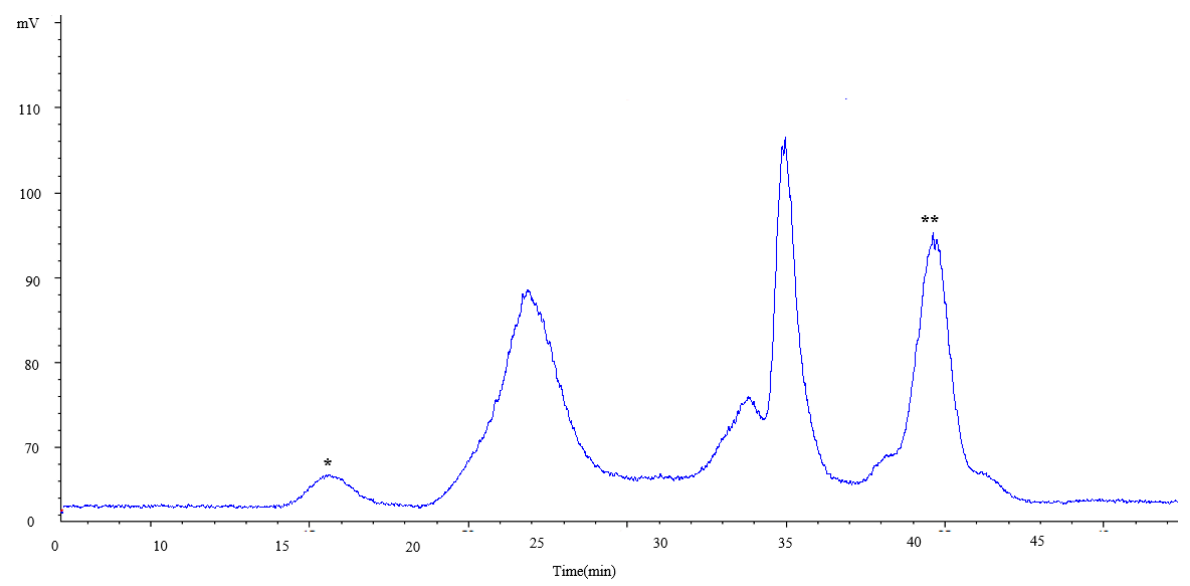

Figure 5. HPSEC-ELSD profile of the carbohydrate fraction corresponding to bioactive component extractions at $110{ }^{\circ} \mathrm{C}$ with $50 \%$ of EtOH. Peaks labeled as * and ${ }^{* *}$ were out of the range of estimation of the method.

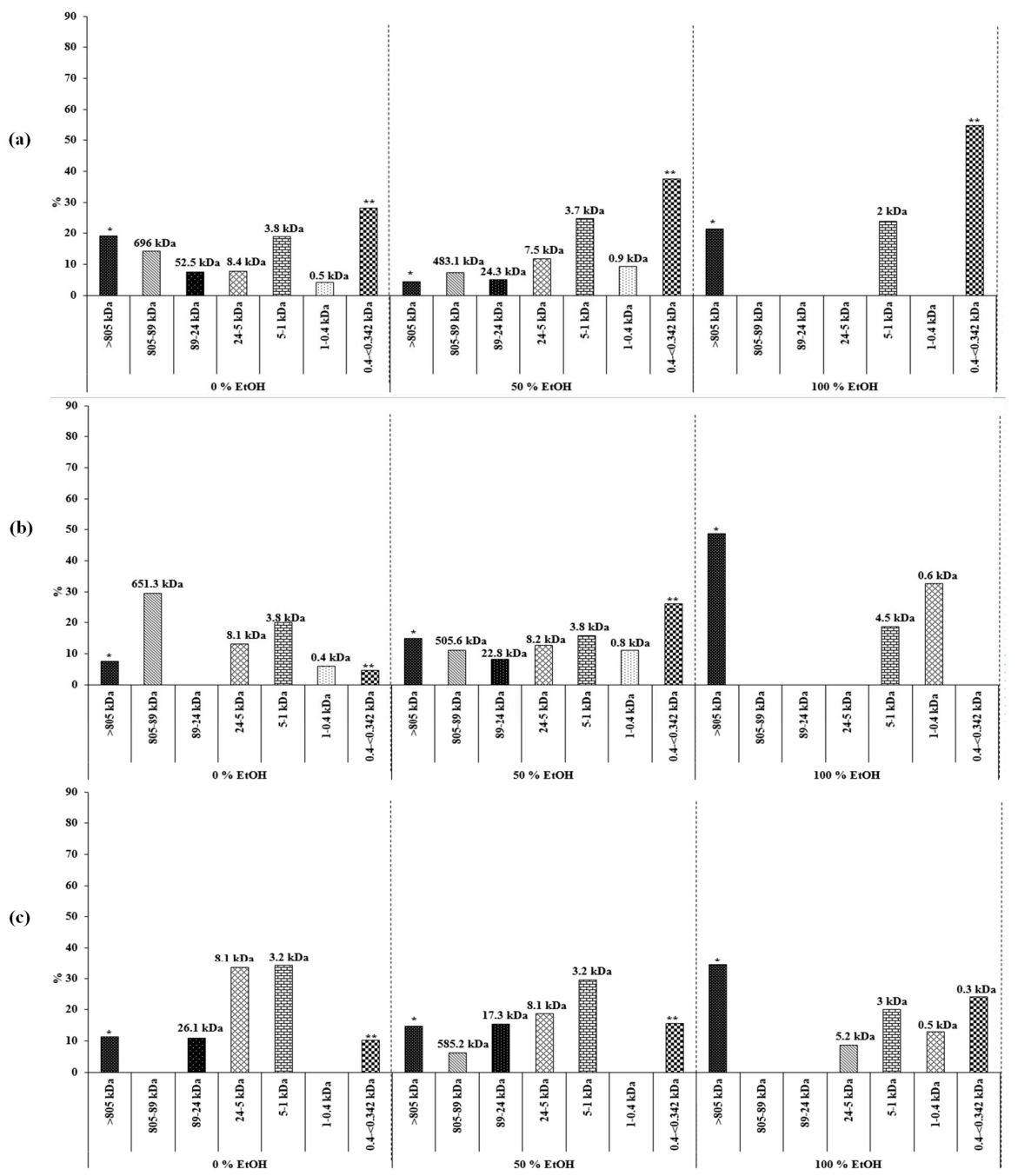

Figure 6. Distribution and abundance of the different carbohydrate fractions according to the estimations of the molecular weight (Mw) obtained by HPSEC-ELSD of the extractions carried out at $40(\mathbf{a}), 110(\mathbf{b})$, and $180^{\circ} \mathrm{C}(\mathbf{c})$. 
With the aim to gain more insight on the structure of the carbohydrates extracted from E. cantabrica, in the present work, we have carried out a quantification of the monomeric composition of the polymers. For this purpose, a previous hydrolysis step with trifluoroacetic acid (TFA) was necessary. The monosaccharides were derivatized and analyzed as trimethylsilyl (TMS) oximes by gas chromatography with flame ionization detection (GC-FID). Figure 7 shows the chromatographic profile of monosaccharides that constitute the carbohydrate polymers extracted by PLE from E. cantabrica.

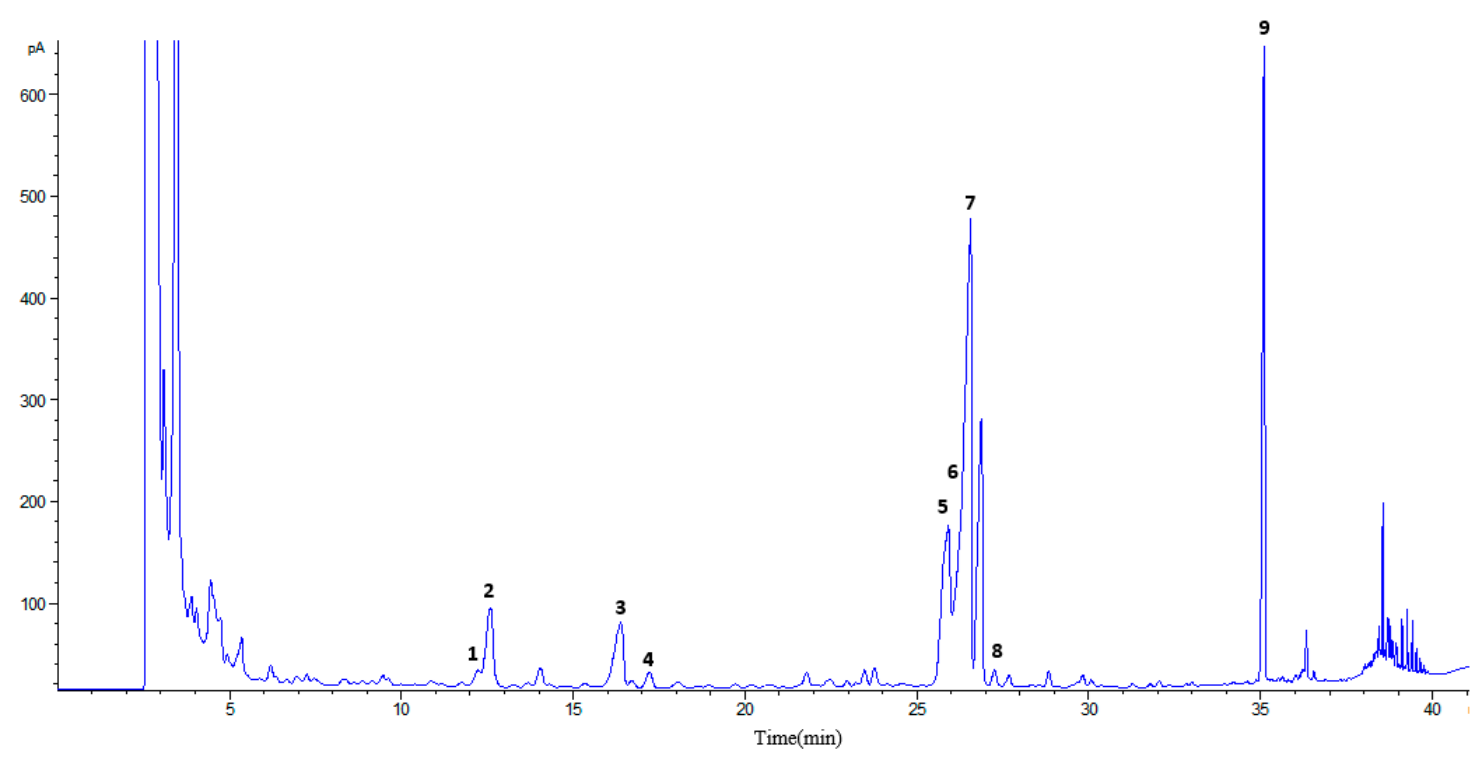

Figure 7. Chromatographic profile obtained by gas chromatography with flame ionization detection (GC-FID) of trimethylsilyl (TMS) oxymes of monosaccharides after hydrolysis with 2-N trifluoroacetic acid (TFA) of extracted pectin from Euglena cantabrica by PLE (110 ${ }^{\circ} \mathrm{C}$ with $50 \%$ of EtOH). (1) Xylose (Xyl), (2) xylose+arabinose (Xyl+Ara), (3) rhamnose (Rha), (4) fucose (Fuc), (5) galactose (Gal), (6) mannose (Man), (7) glucose (Glc), (8) galacturonic acid (Gal A), and (9) internal standard.

The most striking feature was the presence of elevated amounts of glucose, which is the unique monosaccharide present in paramylon, which, in Euglena spp., is a chain without branching. In addition, most of the extractions gave rise to the presence of xylose, arabinose, fucose, galactose, and mannose in variable concentrations (see Figure 8 and Table 3). O'Neill et al. [30] carried out an exhaustive study on the huge availability of $E$. gracilis for the synthesis of complex glycans and found that polymers related to xylan, mannan, arabinan, and arabinogalactan can be also present. Moreover, at the base of the flagella, some $\alpha$-glucose and $\alpha$-mannose residues could be at the fission point. Additionally, the N-glucan analysis of all the Euglena samples studied by these authors demonstrated that mannose is the unique monosaccharide constituting $\mathrm{N}$-glycans and that the surface of $E$. gracilis has some xylanand arabinan-type materials.

It is possible to conclude that, undoubtedly, E. cantabrica is a rich source of interesting carbohydrates with bioactive properties, although more studies are needed to exhaustively characterize the structure of all the glycans present. It seems clear that not a single family of compounds is responsible for the antioxidant capacity but the relative amount of carbohydrates, phenolic compounds, and pigments. 


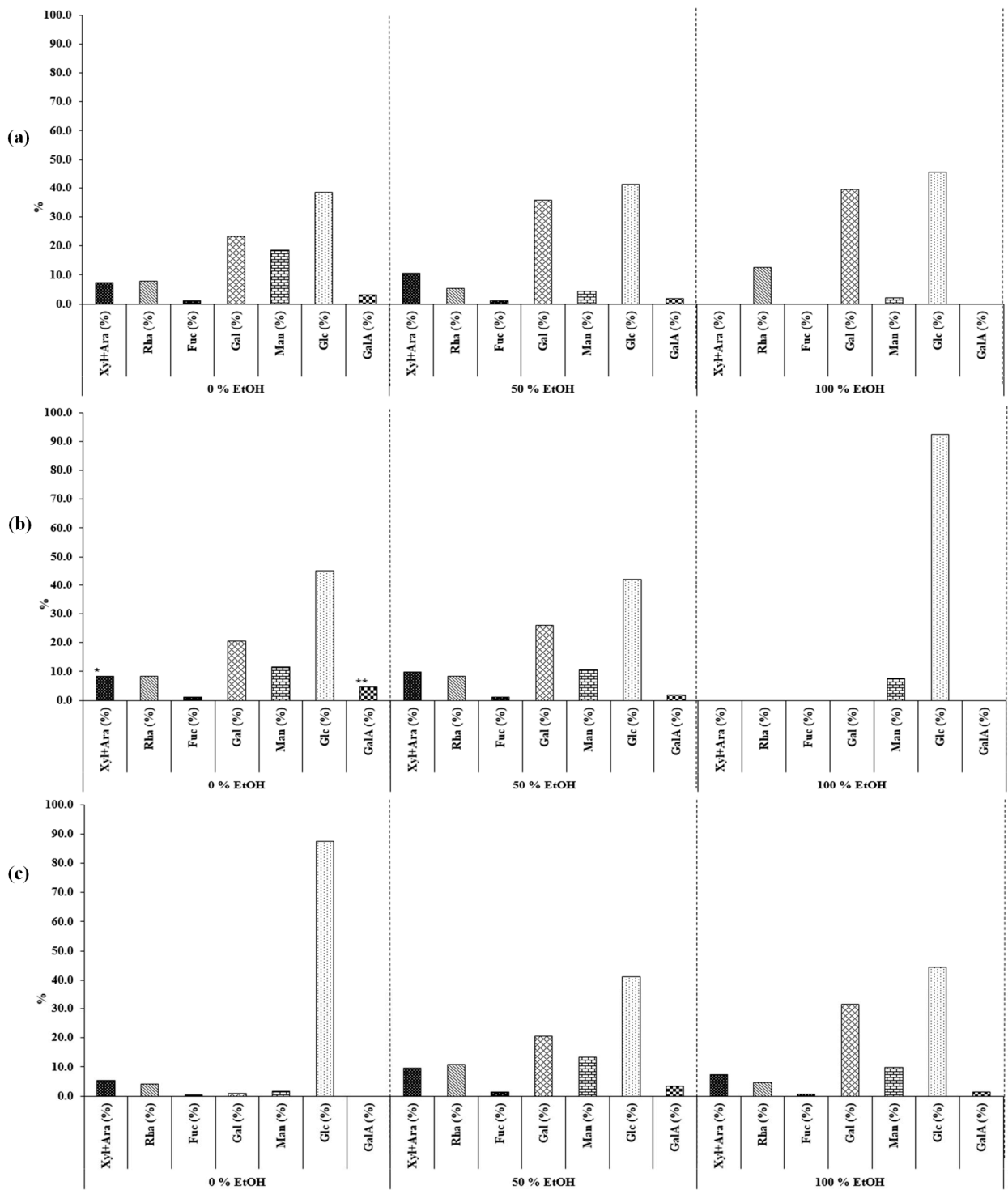

Figure 8. Distribution and abundance of the monomeric compositions (\% over total carbohydrates) obtained by GC-FID after the hydrolysis with TFA of the extractions carried out at 40 (a), 110 (b), and $180{ }^{\circ} \mathrm{C}(\mathbf{c})$.

Table 3. Distribution of the molecular weights and abundance of the monomeric composition (\% over total carbohydrates) obtained by gas chromatography with flame ionization detection (GC-FID) after the hydrolysis with trifluoroacetic acid (TFA) of the extractions was carried out at different temperatures and solvent compositions.

\begin{tabular}{ccccccccc}
\hline \multirow{2}{*}{ Temp. } & \multirow{2}{*}{ Solvent } & \multicolumn{7}{c}{ Molecular weights of the carbohydrate fractions } \\
\cline { 2 - 9 } & & $>805 \mathrm{kDa}$ & $804-89 \mathrm{kDa}$ & $89-24 \mathrm{kDa}$ & $24-5 \mathrm{kDa}$ & $5-1 \mathrm{kDa}$ & $1-0.4 \mathrm{kDa}$ & $0.39-<0.342 \mathrm{kDa}$ \\
\hline \multirow{3}{*}{$40{ }^{\circ} \mathrm{C}$} & $0 \% \mathrm{EtOH}$ & $>805(18 \%)$ & $696(14 \%)$ & $52.5(8 \%)$ & $8.4(8 \%)$ & $3.8(19 \%)$ & $0.5(4 \%)$ & $<0.342(29 \%)$ \\
\cline { 2 - 8 } & $50 \% \mathrm{EtOH}$ & $>805(4 \%)$ & $483.1(8 \%)$ & $24.3(5 \%)$ & $7.5(12 \%)$ & $3.7(24 \%)$ & $0.9(9 \%)$ & $<0.342(38 \%)$ \\
\cline { 2 - 9 } & $100 \% \mathrm{EtOH}$ & $>805(21 \%)$ & - & - & - & $2(24 \%)$ & - & $<0.342(55 \%)$ \\
\hline \multirow{3}{*}{$110{ }^{\circ} \mathrm{C}$} & $0 \% \mathrm{EtOH}$ & $>805(9 \%)$ & $651.3(32 \%)$ & - & $8.1(17 \%)$ & $3.8(25 \%)$ & $0.4(8 \%)$ & $<0.342(7 \%)$ \\
\cline { 2 - 9 } & $50 \% \mathrm{EtOH}$ & $>805(15 \%)$ & $505.6(11 \%)$ & $22.8(9 \%)$ & $8.2(12 \%)$ & $3.8(16 \%)$ & $0.8(12 \%)$ & $<0.342(25 \%)$ \\
\cline { 2 - 8 } & $100 \% \mathrm{EtOH}$ & $>805(49 \%)$ & - & - & - & $4.5(19 \%)$ & $0.6(32 \%)$ & - \\
\hline \multirow{3}{*}{$180{ }^{\circ} \mathrm{C}$} & $0 \% \mathrm{EtOH}$ & $>805(11 \%)$ & - & $26.1(10 \%)$ & $8.1(35 \%)$ & $3.2(35 \%)$ & - & $<0.342(9 \%)$ \\
\cline { 2 - 8 } & $50 \% \mathrm{EtOH}$ & $>805(14 \%)$ & $585.2(5 \%)$ & $17.3(16 \%)$ & $8.1(19 \%)$ & $3.2(30 \%)$ & - & $<0.342(16 \%)$ \\
\hline & $100 \% \mathrm{EtOH}$ & $>805(36 \%)$ & - & - & $5.2(9 \%)$ & $3(21 \%)$ & $0.5(12 \%)$ & $<0.342(22 \%)$ \\
\hline
\end{tabular}




\section{Materials and Methods}

\subsection{Strain, Culture Conditions, and Breaking of the Cell Wall}

Euglena cantabrica (BEA 0937B) clonal strains were provided by the culture collection at the Spanish Bank of Algae (BEA) in Gran Canaria (Spain). The algae were cultivated at natural conditions with a light intensity media of $134.3 \mathrm{~W} / \mathrm{m}^{2}$ and at a temperature media of $24^{\circ} \mathrm{C}$. The cultures were done with a dark:light cycle media of 12.5:11.5. Then, the cell wall of the alga was broken at 1500 bar (high-pressure homogenization). After this, the frozen paste was lyophilized before extraction. Methanol and Methyl tert-butyl ether (MTBE) were HPLC quality, from VWR (Avantor, West Chester, Pensilvania, USA)

\subsection{Pressurized Liquid Extraction}

The extractions were done in an ASE 200 (Accelerated Solvents Extractor, Dionex, Sunnyvale, CA, USA) with the conditions established in the factorial $3^{2}$ DoE. Extraction temperature $\left(40-180{ }^{\circ} \mathrm{C}\right)$ and solvent composition ( $0-100 \%$ ethanol in water) were the two experimental factors under study. The order of the experiments was randomized by the statistical software Statgraphics Centurion (version XVI) to avoid the error due to incontrollable parameters. Cross-contamination between experiments was prevented by a cleaning protocol (a blank extraction) after each extraction. All the extractions of E. cantabrica were done using $1 \mathrm{~g}$ of freeze-dried disrupted microalgae mixed with $2 \mathrm{~g}$ of sea sand. Extraction time was $20 \mathrm{~min}$ for all extractions, because it was demonstrated that the extraction time above $15 \mathrm{~min}$ does not have statistical influence in the yield or the antioxidant capacity [15]. Pressure was constant (10 MPa) in order to keep solvents in a liquid phase under all temperatures tested. Solvent was removed to calculate the extraction yield: ethanol was evaporated under a nitrogen stream, and water was freeze-dried.

\subsection{Chemical Characterization and Evaluation of the Antioxidant Capacity}

\subsubsection{Total Phenols Content (TPC): Folin-Ciocalteau Test}

The total content of phenols was measured as mg of GAE (gallic acid equivalents)/g extract, according to the protocol developed by Kosar et al. [31], with some modifications [21]. Phenols existing in algae extracts were able to reduce $\mathrm{Mo}(\mathrm{VI})$ to $\mathrm{Mo}(\mathrm{V})$ present in the Folin-Ciocalteau reagent. The intensity of the blue color generated (absorbance at $760 \mathrm{~nm}$ ) was related to the concentration of phenols in the extract. Briefly, an aliquot $(10 \mu \mathrm{L})$ of extract solution (5 to $10 \mathrm{mg}$ extract $/ \mathrm{mL}$ ) was deposited in an Eppendorf type tube together with $600 \mu \mathrm{L}$ of ultrapure water. To this mixture, $50 \mu \mathrm{L}$ of undiluted Folin-Ciocalteau reagent (Merck, Darmstadt, Germany) and $150 \mu \mathrm{L}$ of $20 \%$ (w/v) $\mathrm{Na}_{2} \mathrm{CO}_{3}$ ( $1 \mathrm{~min}$ later) were subsequently added, and the volume was made up to $1 \mathrm{~mL}$ with ultrapure water. The mixture was vortexed and incubated for $2 \mathrm{~h}$ at room temperature in the darkness. Finally, $300 \mu \mathrm{L}$ of each reaction mixture was transferred to a 96-well plate to measure the absorbance at $760 \mathrm{~nm}$ (microplate spectrophotometer reader Synergy HT, BioTek Instruments, Winooski, VT, USA). Gallic acid was used as a reference standard for calibration $\left(0.031-2 \mathrm{mg} \mathrm{mL}^{-1}\right)$.

\subsubsection{Antioxidant Capacity: ABTS Test}

The ABTS (2,2'-azino-bis(3-ethylbenzothiazoline-6-sulfonic acid) diammonium salt) test was performed according to the procedure developed by Re et al. [32], with some modifications [21]. First, $\mathrm{ABTS}^{\bullet+}$ radicals were generated by a reaction of ABTS $(7 \mathrm{mM})$ with potassium persulfate $(2.45 \mathrm{mM})$ in the dark at room temperature for $16 \mathrm{~h}$. The radical solution was diluted with sodium phosphate buffer ( $5 \mathrm{mM}, \mathrm{pH} 7.4)$ to an absorbance value of $0.7( \pm 0.02)$ measured at $734 \mathrm{~nm}$. Then, the inhibition of the diluted radical solution by the different algae extracts $\left(10 \mu \mathrm{L}\right.$ of extract mixed with $1 \mathrm{~mL}$ of ABTS $^{\bullet+}$ solution) was measured after $45 \mathrm{~min}$ of incubation. To this aim, five different dilutions of each extract giving a linear response between $20 \%$ and $80 \%$ of the blank absorbance were analyzed in triplicate. Results were expressed as TEAC values (mmol Trolox equivalents (TE)/g samples), since Trolox 
was used as the reference standard. The scavenging of the DPPH (1,1-diphenyl-2-picrylhydrazyl) radical was based on the procedure developed by Brand-Williams et al. [33], modified by the authors of [34]. Briefly, the inhibition of a solution of the radical by the different algae extracts was measured (absorbance at $516 \mathrm{~nm}$ ) after $4 \mathrm{~h}$ of incubation. To do this, different dilutions of E. cantabrica PLE extracts $(10 \mu \mathrm{L})$ were mixed with a solution of $60 \mu \mathrm{M} \mathrm{DPPH}(290 \mu \mathrm{L})$, and the absorbance after the incubation time was compared against a calibration curve of DPPH prepared in methanol $(7.5-90 \mu \mathrm{M})$. Results are expressed as the effective concentration of extract able to decrease the concentration of DPPH to the half (EC50).

\subsubsection{Total Lipids}

The total content of lipids was measured by weighing the dried extract obtained with methanol: chloroform (2:1), following the gravimetric protocol of Aselsson and Gentili [35].

\subsubsection{Carotenoids and Chlorophylls}

The analysis of pigments was done using a procedure based on high-performance liquid chromatography coupled to a diode array detector and atmospheric pressure chemical ionization tandem mass spectrometry (HPLC-DAD-APCI-MS/MS). The procedure followed was a modification of the method developed by Castro-Puyana et al. [16]. Analyses of the extracts were conducted using a HPLC 1100 series (Agilent Technologies, Santa Clara, CA, USA) equipped with a diode array detector and coupled to an ion trap mass spectrometer (Esquire 2000, Bruker, Bremen, Germany) via an atmospheric pressure chemical ionization (APCI) interface. Separation of pigments was carried out in a YMC-C30 reversed-phase column $(250 \mathrm{~mm} \times 4.6 \mathrm{~mm}$ inner diameter, $5-\mu \mathrm{m}$ particle size; YMC Europe, Schermbeck, Germany) protected by a pre-column YMC-C30 (10 mm $\times 4 \mathrm{~mm}$ i.d., $5 \mu \mathrm{m})$. The mobile phase was a mixture of methanol-MTBE-water $(90: 7: 3 \mathrm{v} / \mathrm{v} / \mathrm{v})($ solvent A) and methanol-MTBE (10:90 v/v) (solvent B). Mobile phase was flowing at $0.8 \mathrm{~mL} \mathrm{~min}^{-1}$ according to the following gradient: $0 \mathrm{~min}, 0 \% \mathrm{~B} ; 15 \mathrm{~min}, 17 \% \mathrm{~B} ; 20 \mathrm{~min}, 17 \% \mathrm{~B} ; 30 \mathrm{~min}, 25 \% \mathrm{~B} ; 35 \mathrm{~min}, 55 \% \mathrm{~B} ; 45 \mathrm{~min}$, $85 \% \mathrm{~B} ; 50 \mathrm{~min}, 100 \% \mathrm{~B} ; 60 \mathrm{~min}, 100 \% \mathrm{~B}$; and $62 \mathrm{~min}, 0 \% \mathrm{~B}$. The injection volume was $10 \mu \mathrm{L}$. UV-Vis spectra from 240 to $770 \mathrm{~nm}$ were collected using the DAD (peak width $>0.1$ min (2 s), slit $4 \mathrm{~nm}$ ), and chromatographic profiles were recorded at 450 and $660 \mathrm{~nm}$. Full-scan spectrum was acquired in the range of $m / z$ 150-1300. Automatic MS/MS analyses were also performed, fragmenting the two highest precursor ions (10,000-count threshold; 1-V fragmentor amplitude). Data were processed by ChemStation software from Agilent Technologies (Rev. B.04.03) and DataAnalysis from Bruker GmbH (version 3.2).

\subsubsection{Carbohydrates}

\section{Estimation of Molecular Weight (Mw)}

The Mw distributions were estimated following the method described by Muñoz-Almagro et al. (2018). Samples $(0.1 \% \mathrm{w} / \mathrm{v}, 50 \mu \mathrm{L})$ were eluted using a TSK-Gel guard column $(6.0 \mathrm{~mm} \times 400 \mathrm{~mm})$ and two TSK-Gel columns connected in series G5000 PWXL $(7.8 \mathrm{~mm} \times 300 \mathrm{~mm}, 10 \mu \mathrm{m})$ and G2500 PWXL (7.8 mm $\times 300 \mathrm{~mm}, 6 \mu \mathrm{m}$ ) (Tosoh Bioscience, Stuttgart, Germany). The mobile phase was 0.01-M $\mathrm{NH}_{4}$ Ac as the mobile phase and pectin samples were separated at $0.5 \mathrm{~mL} / \mathrm{min}$ and $30^{\circ} \mathrm{C}$ during $50 \mathrm{~min}$. Dextran blue was used for the establishment of the exclusion volume of the columns (1000 kDa). For the calibrations, a Pullulan Standard Set (Sigma, St. Louis, MO, USA) was used. The average molecular weight $(\mathrm{Mw})$ of the different pullulans were $0.342 \mathrm{kDa} ; 1.32 \mathrm{kDa}, 6.20 \mathrm{kDa}$, and $10 \mathrm{kDa}$; $21.7 \mathrm{kDa} ; 48.8 \mathrm{kDa} ; 113 \mathrm{kDa} ; 200 \mathrm{kDa}$; and $348 \mathrm{kDa}$ and $805 \mathrm{kDa}$.

\section{Determination of Monomeric Composition}

Before pectin derivatization, a hydrolysis with TFA $2 \mathrm{~N} 110{ }^{\circ} \mathrm{C}$ was carried out following the method reported by Muñoz-Almagro et al. [36]. Samples were eluted using a DB-5HT column 
$(15 \mathrm{~m} \times 0.32 \mathrm{~mm} \times 0.10 \mu \mathrm{m}, \mathrm{J} \& W$ Agilent, Folson, CA, USA) and split 1:5. The flow of nitrogen was $1 \mathrm{~mL} / \mathrm{min}$. The temperatures of the injector and detector were kept at 280 and $350{ }^{\circ} \mathrm{C}$, respectively; the temperature program started at $150{ }^{\circ} \mathrm{C}$ and raised to $165^{\circ} \mathrm{C}$ at $1{ }^{\circ} \mathrm{C} / \mathrm{min}$ and up to $300{ }^{\circ} \mathrm{C}$ at $10^{\circ} \mathrm{C} / \mathrm{min}$. For identification and quantitation, standard solutions of xylose, arabinose, rhamnose, fucose, galactose, mannose, glucose, and galacturonic acid over the expected concentration range in extracts of samples were injected and analyzed to calculate the response factor relative to phenyl- $\beta$-D-glucoside (internal standard, $0.05 \% \mathrm{w} / \mathrm{v}$ ).

\section{Conclusions}

Pressurized liquid extraction using green solvents, such as water and ethanol mixtures, has demonstrated its potential to obtain different extracts of interest from Euglena cantabrica. Extracts with high antioxidant capacities can be obtained at $180{ }^{\circ} \mathrm{C}$ with $41.1 \% \mathrm{EtOH}$, according to the response surface obtained from the statistical analysis of the DoE. The presence of natural pigments such as pheophytins and the carotenoid diatoxanthin (previously reported in E. sanguinea) in extracts obtained with pure ethanol has been confirmed by using HPLC-DAD-MS/MS. On the other hand, the bioactive carbohydrate paramylon was more efficiently extracted at $110^{\circ} \mathrm{C}$ using $50 \% \mathrm{EtOH}$, as it has been revealed using HPSEC-ELSD and GC-FID. This is the first study on the application of pressurized green extraction techniques to the scarcely investigated Euglena cantabrica, which increases the knowledge about its chemical composition and opens a huge potential of the application of this microalga for food and pharmacological uses. Biorefinery approaches based on green pressurized technologies should be further investigated, since the results of this screening show that the modulation of the extraction conditions may lead to a selective fractionation of E. cantabrica biomass, in order to develop a green downstream platform that yields several fractions with different industrial applications.

Author Contributions: B.G.-L., E.I., M.V., and J.A.M. contributed to planning the experiments. Y.G.-F. and C.A. contributed to experimental culturing of Euglena cantabrica. P.-R.M.C. and N.M.-A. carried out most of the experimental tasks. B.G.-L., N.M.-A., and J.A.M. processed the analytical data. All authors contributed equally to writing the manuscript. All authors have read and agreed to the published version of the manuscript.

Funding: The authors acknowledge funding from the European Union (EU) (FP7 MIRACLES Project-grant agreement no. 613588, H2020 ABACUS Project-grant agreement no. 745668), and MINECO of Spain, Project AGL2014-53445-R.

Acknowledgments: N.M.-A. thanks the Ministry of Economy of Spain for providing her FPI predoctoral fellowship.

Conflicts of Interest: The authors declare no conflicts of interest.

\section{References}

1. Allen, E.J.; Allen, E.J.; Nelson, E.W. On the artificial culture of marine plankton organisms. J. Mar. Biol. Assoc. U.K. 1910, 8, 421-474. [CrossRef]

2. Herrero, M.; Sánchez-Camargo, A.P.; Cifuentes, A.; Ibáñez, E. Plants, seaweeds, microalgae and food by-products as natural sources of functional ingredients obtained using pressurized liquid extraction and supercritical fluid extraction. TRAC-Trends Anal. Chem. 2015, 71, 26-38. [CrossRef]

3. Mobin, S.; Alam, F. Some Promising Microalgal Species for Commercial Applications: A review. Energy Procedia 2017, 110, 510-517. [CrossRef]

4. Watanabe, T.; Shimada, R.; Matsuyama, A.; Yoshida, E.; Suzuki, K. Antitumor activity of the $\beta$-glucan paramylon from Euglena against preneoplastic colonic aberrant crypt foci in mice. Food Funct. 2013, 4, 1685-1690. [CrossRef] [PubMed]

5. Kottuparambil, S.; Thankamony, R.L.; Agusti, S. Euglena as a potential natural source of value-added metabolites. A review. Algal Res. 2019, 37, 154-159. [CrossRef]

6. Shin, W.; Triemer, R.E. Phylogenetic analysis of the genus Euglena (Euglenophyceae) with particular reference to the type species Euglena viridis. J. Phycol. 2004, 40, 759-771. [CrossRef] 
7. Kosmala, S.; Karnkowska-Ishikawa, A.; Milanowski, R.; Kwiatowski, J.; Zakry's, B. Phylogeny and systematics of Euglena (Euglenaceae) species with axial, stellate chloroplasts based on morphological and molecular data-new taxa, emended diagnoses, and epitypifications. J. Phycol. 2009, 45, 464-481. [CrossRef]

8. Kim, J.I.; Linton, E.W.; Shin, W. Taxon-rich multigene phylogeny of the photosynthetic euglenoids (Euglenophyceae). Front. Ecol. Evol. 2015, 3, 98. [CrossRef]

9. Suzuki, K.; Arashida, R.; Marukawa, Y.; Yoshida, E.; Takeda, T.; Nakano, Y.; Konno, N.; Takahashi, M. B-1,3-Glucanase, Polynucleotide, Recombinant Vector, Transformant, Production Method for B-1,3-Glucanase, Enzyme Preparation, and Production Method for Paramylon having Reduced Molecular Weight. U.S. Patent US9644193B2, 9 May 2017.

10. Borowitzka, M.A. Biology of Microalgae in Health and Disease Prevention; Academic Press: Cambridge, MA, USA, 2018; pp. 23-72.

11. Deli, J.; Gonda, S.; Nagy, L.Z.; Szabó, I.; Gulyás-Fekete, G.; Agócs, A.; Marton, K.; Vasas, G. Carotenoid composition of three bloom-forming algae species. Food Res. Int. 2014, 65, 215-223. [CrossRef]

12. Jerez-Martel, I.; García-Poza, S.; Rodríguez-Martel, G.; Rico, M.; Afonso-Olivares, C.; Gómez-Pinchetti, J.L. Phenolic Profile and Antioxidant Activity of Crude Extracts from Microalgae and Cyanobacteria Strains. J. Food Qual. 2017, 2924508. [CrossRef]

13. Grosso, C.; Valentão, P.; Ferreres, F.; Andrade, P.B. Alternative and efficient extraction methods for marine-derived compounds. Mar. Drugs 2015, 13, 3182-3230. [CrossRef] [PubMed]

14. Herrero, M.; Castro-Puyana, M.; Mendiola, J.A.; Ibáñez, E. Compressed fluids for the extraction of bioactive compounds. TRAC-Trends Anal. Chem. 2013, 43, 67-83. [CrossRef]

15. Herrero, M.; Jaime, L.; Martín-Álvarez, P.J.; Cifuentes, A.; Ibáñez, E. Optimization of the extraction of antioxidants from Dunaliella salina microalga by pressurized liquids. J. Agric. Food Chem. 2006, 54, 5597-5603. [CrossRef] [PubMed]

16. Castro-Puyana, M.; Herrero, M.; Urreta, I.; Mendiola, J.A.; Cifuentes, A.; Ibáñez, E.; Suárez-Alvarez, S. Optimization of clean extraction methods to isolate carotenoids from the microalga Neochloris oleoabundans and subsequent chemical characterization using liquid chromatography tandem mass spectrometry. Anal. Bioanal. Chem. 2013, 405, 4607-4616. [CrossRef] [PubMed]

17. Gilbert-López, B.; Barranco, A.; Herrero, M.; Cifuentes, A.; Ibáñez, E. Development of new green processes for the recovery of bioactives from Phaeodactylum tricornutum. Food Res. Int. 2017, 99, 1056-1065. [CrossRef] [PubMed]

18. Zainan, N.H.; Thiruvenkadam, S.; Danquah, M.K.; Harun, R. Biochemical analysis and potential applications of aqueous and solid products generated from subcritical water extraction of microalgae Chlorella pyrenoidosa biomass. J. Appl. Phycol. 2020, 32, 111-126. [CrossRef]

19. Golmakani, M.T.; Mendiola, J.A.; Rezaei, K.; Ibáñez, E. Pressurized limonene as an alternative bio-solvent for the extraction of lipids from marine microorganisms. J. Supercrit. Fluid. 2014, 92, 1-7. [CrossRef]

20. Gilbert-López, B.; Mendiola, J.A.; Fontecha, J.; van den Broek, L.A.; Sijtsma, L.; Cifuentes, A.; Ibáñez, E. Downstream processing of Isochrysis galbana: A step towards microalgal biorefinery. Green Chem. 2015, 17, 4599-4609. [CrossRef]

21. Gilbert-López, B.; Mendiola, J.A.; van den Broek, L.A.M.; Houweling-Tan, B.; Cifuentes, A.; Herrero, M.; Ibáñez, E. Green compressed fluid technologies for downstream processing of Scenedesmus obliquus in a biorefinery approach. Algal Res. 2017, 24, 111-121. [CrossRef]

22. Britton, G.; Liaaen-Jensen, S. Carotenoids Handbook; Pfander, H., Ed.; Birkhäuser: Basel, Switzerland, 2004.

23. Huang, S.C.; Hung, C.F.; Wu, W.B.; Chen, B.H. Determination of chlorophylls and their derivatives in Gynostemma pentaphyllum Makino by liquid chromatography-mass spectrometry. J. Pharm. Biomed. Anal. 2008, 48, 105-112. [CrossRef]

24. Chen, K.; Ríos, J.J.; Roca, M.; Pérez-Gálvez, A. Development of an accurate and high-throughput methodology for structural comprehension of chlorophylls derivatives. (II) Dephytylated derivatives. J. Chromatogr. A 2015, 1412, 90-99. [CrossRef]

25. Viera, I.; Roca, M.; Perez-Galvez, A. Mass spectrometry of non-allomerized chlorophylls a and b derivatives from plants. Curr. Org. Chem. 2018, 22, 842-876. [CrossRef]

26. Takaichi, S. Carotenoids in algae: Distributions, biosyntheses and functions. Mar. Drugs 2011, 9, 1101-1118. [CrossRef] [PubMed] 
27. Kato, S.; Soshino, M.; Takaichi, S.; Ishikawa, T.; Nagata, N.; Asahina, M.; Shinomura, T. Suppression of the phytoene synthase gene (EgcrtB) alters carotenoid content and intracellular structure of Euglena gracilis. BMC Plant Biol. 2017, 17, 125. [CrossRef] [PubMed]

28. Nakashima, A.; Sugimoto, R.; Suzuki, K.; Shirakata, Y.; Hashiguchi, T.; Yoshida, C.; Nakano, Y. Anti-fibrotic activity of Euglena gracilis and paramylon in a mouse model of non-alcoholic steatohepatitis. Food Sci. Nutr. 2018, 7, 139-147. [CrossRef] [PubMed]

29. Gissibl, A.; Care, A.; Parker, L.M.; Iqbal, S.; Hobba, G.; Nevalainen, H.; Sunna, A. Microwave pretreatment of paramylon enhances the enzymatic production of soluble $\beta$-1,3-glucans with immunostimulatory activity. Carbohydr. Polym. 2018, 196, 339-347. [CrossRef] [PubMed]

30. O'Neill, E.C.; Kuhaudomlarp, S.; Rejzek, M.; Fangel, J.U.; Alagesan, K.; Kolarich, D.; Willats, W.G.T.; Field, R.A. Exploring the Glycans of Euglena gracilis. Biology 2017, 6, 45. [CrossRef] [PubMed]

31. Koşar, M.; Dorman, H.J.D.; Hiltunen, R. Effect of an acid treatment on the phytochemical and antioxidant characteristics of extracts from selected Lamiaceae species. Food Chem. 2005, 91, 525-533.

32. Re, R.; Pellegrini, N.; Proteggente, A.; Pannala, A.; Yang, M.; Rice-Evans, C. Antioxidant activity applying an improved ABTS radical cation decolorization assay. Free Radic. Biol. Med. 1999, 26, 1231-1237. [CrossRef]

33. Brand-Williams, W.; Cuvelier, M.E.; Berset, C. Use of a free radical method to evaluate antioxidant activity. LWT-Food Sci. Technol. 1995, 28, 25-30. [CrossRef]

34. Nabet, N.; Gilbert-López, B.; Madani, K.; Herrero, M.; Ibáñez, E.; Mendiola, J.A. Optimization of microwave-assisted extraction recovery of bioactive compounds from Origanum glandulosum and Thymus fontanesii. Ind. Crop. Prod. 2020, 129, 395-404. [CrossRef]

35. Axelsson, M.; Gentili, F. A single-step method for rapid extraction of total lipids from green microalgae. PLoS ONE 2004, 9, e89643. [CrossRef] [PubMed]

36. Muñoz-Almagro, N.; Valadez-Carmona, L.; Mendiola, J.A.; Ibáñez, E.; Villamiel, M. Structural characterisation of pectin obtained from cacao pod husk. Comparison of conventional and subcritical water extraction. Carbohydr. Polym. 2019, 217, 69-78. [CrossRef] [PubMed]

(C) 2020 by the authors. Licensee MDPI, Basel, Switzerland. This article is an open access article distributed under the terms and conditions of the Creative Commons Attribution (CC BY) license (http://creativecommons.org/licenses/by/4.0/). 